\title{
AMMI confounded with BLUP of feed barley genotypes for superiority measures under NEPZ trials
}

\author{
Ajay Verma*, R.P.S. Verma, J. Singh, L. Kumar and G.P. Singh \\ ICAR-Indian Institute of Wheat and Barley Research, Karnal (Haryana) India \\ (Email: verma.dwr@gmail.com)
}

\begin{abstract}
AMMI analysis of feed barley genotypes evaluated for North Eastern Plains Zone of the country observed highly significant effects of environments (E), GxE interaction and genotypes $(\mathrm{G})$. GxE Interaction effects accounted for $45.9 \%$ and $29.2 \%$ and environment effects explained $27.5 \%$ and $37.1 \%$, during cropping seasons of 2018-19 and 2019-20, respectively. ASTAB measure achieved the desirable lower values for HUB113, DWRB137. Ranks of MASV1 and MASV measures considered HUB113, K508 genotypes would be of choice this zone. Superiority index assigned 0.65 and 0.35 weights for average yield and stability found HUB113, DWRB137 as of stable performance with high yield. Biplot graphical analysis as per $84.7 \%$ of variation of the measures exhibited largest cluster comprised of MASV1 with ASTAB, EV, SIPC, Za, W2, WAASB and MASV measures. For the second-year Desirable lower values of ASTAB measure achieved by HUB69, Lakhan, RD3020. Ranks of composite measure MASV1 and MASV found Lakhan, HUB69, KB1830 genotypes would be of choice for these locations. Superiority index with assigned weights for yield and stability found Lakhan, DWRB213, KB1830 as of stable performance with high yield. About 79.3 $\%$ of variation of the measures under biplot analysis observed AMMI based measures were grouped together and mean yield joined hands with superiority measures of genotypes. The reliability of multi-locations trials would be increased with superiority Indexes as major features of AMMI and BLUP had been confounded. Option of assigning variable weights to the yield and stable performance help the researches to set their crop improvement targets.
\end{abstract}

Key Words : AMMI, ASV, ASV1, HMGV, GAI, HMPRVG, Biplots

View Point Article : Verma, Ajay, Verma, R.P.S., Singh, J., Kumar, L. and Singh, G.P. (2021). AMMI confounded with BLUP of feed barley genotypes for superiority measures under NEPZ trials. Internat. J. agric. Sci., 17 (2) : 573-581, DOI:10.15740/HAS/IJAS/17.2/573-581. Copyright@ 2021: Hind Agri-Horticultural Society.

Article History : Received : 21.03.2021; Revised : 24.03.2021; Accepted : 02.04.2021

\footnotetext{
* Author for correspondence :
} 